\title{
Article \\ A Robust Payload Control System Design for Offshore Cranes: Experimental Study
}

\author{
Hwan-Cheol Park ${ }^{1}$, Soumayya Chakir ${ }^{2} \oplus$, Young-Bok Kim ${ }^{2}{ }^{\circledR}$ and Dong-Hun Lee ${ }^{2, *}$ \\ 1 Ship Training and Operations Center, Pukyong National University, Busan 48513, Korea; \\ phc1120@hanmail.net \\ 2 Department of Mechanical System Engineering, Pukyong National University, Busan 48513, Korea; \\ soumayya.chakir@gmail.com (S.C.); kpjiwoo@pknu.ac.kr (Y.-B.K.) \\ * Correspondence: iottoi@pukyong.ac.kr; Tel.: +82-51-629-6197
}

\section{check for}

updates

Citation: Park, H.-C.; Chakir, S.; Kim, Y.-B.; Lee, D.-H. A Robust Payload Control System Design for Offshore Cranes: Experimental Study. Electronics 2021, 10, 462. https:// doi.org/10.3390/electronics10040462

Academic Editor: Jianxing Liu

Received: 18 January 2021

Accepted: 11 February 2021

Published: 14 February 2021

Publisher's Note: MDPI stays neutral with regard to jurisdictional claims in published maps and institutional affiliations.

Copyright: (c) 2021 by the authors. Licensee MDPI, Basel, Switzerland. This article is an open access article distributed under the terms and conditions of the Creative Commons Attribution (CC BY) license (https:/ / creativecommons.org/licenses/by/ $4.0 /)$.

\begin{abstract}
This paper presents a robust controller design of payload position control for an offshore crane facing disturbance and parametric uncertainties. The offshore operations with cranes while lifting and lowering a payload can be dangerous since safety and efficiency are affected by waves, wind and ocean currents. Such harsh sea conditions put the offshore crane and payload through unwanted disturbances and parametric uncertainties, which requires a robust control system to guarantee reliable performance of these systems. In this paper, we detail a controller designed based on uniformly ultimately bounded (UUB) theory, combined with the input-output linearization control technique (IOLC). The stability of the closed-loop system under the UUB conditions is analyzed using the energy-based Lyapunov function. To evaluate the control performance of the proposed controller, along with an IOLC and an integral sliding mode controller (ISMC), a comparison study is also conducted. The control performance and efficiency of the proposed controller are validated through experiments on an offshore crane model.
\end{abstract}

Keywords: offshore crane; nonlinear analysis; uniformly ultimately bounded; parametric uncertainty

\section{Introduction}

Offshore operations of subsea installations for oil and natural gas extraction and production are becoming increasingly important. Thus, the demand for high-performance offshore cranes is increasing. However, on the sea, various unpredictable disturbances and parametric uncertainties are the main factors influencing the performance of marine systems. For instance, waves, as well as wind and ocean currents, affect the horizontal motions and rotations of a marine vessel. The horizontal motion can be controlled by a dynamic positioning system (DPS). The rotational motion, on the other hand, as well as the heave motion cannot be suppressed with the DPS. The rotational and heave motions have a significant impact on the performance of offshore cranes during subsea lifting operations. Additionally, hydrodynamic forces affect the operability of the offshore crane system. These hydrodynamic forces cannot be measured precisely nor predicted, they may unexpectedly increase or decrease and influence the overall dynamic response of the payload, which leads to undesirable rope tension variations. These factors contribute to the deterioration of the efficiency and the safety of offshore operations, which may also lead to rope rupture. Therefore, in order to robustly track the desired payload position under harsh sea conditions, decoupling the vertical motion of the payload from the rotational and heave motion of the vessel is required, thereby the operability, safety, and efficiency of these operations can be improved.

The efficiency and safety issues of offshore operations have been studied in previous publications. The typical method for actively controlling the load position is active heave compensation (AHC). One of the first AHC configurations was discussed by Southerland [1,2]. Up until now, more advanced algorithms have been proposed for AHC systems to improve 
control performances. For example, in [3-6], linear and nonlinear control schemes of the AHC system were proposed as well as a wave synchronization to minimize the slamming force during the payload water-entry. In [3], a two-phase controller was designed based on the linear control technique. The first phase controller was for heave compensation to keep the variations of the rope tension at a constant value similar to the weight of the payload. With the second phase controller, the relative speed between the payload and sea waves was controlled-wave synchronization. The objective of the latter controller was to ensure a constant velocity of the payload entering the water-entry zone. An extension of the work proposed in [3] was introduced in [4], where the two-phase controller was combined with an adaptive observer to deal with the uncertainty of the plant model. In [5,6], a feedforward control input for wave synchronization combined with linear feedback control input for the AHC system was proposed. However, in these studies, the robustness of the entire controlled system was not guaranteed.

In [7], the authors introduced a nonlinear model and a control technique for active compensation of the heave motion. the heave velocity and the force acting between the AHC unit and the riser/drill string were estimated by a disturbance observer. In [8,9], an input-output linearization control technique (IOLC) including a disturbance decoupling term was combined with a heave motion prediction system to overcome the delay between sensors and actuators. However, none of the aforementioned studies considered the rotational motion of the vessel.

In general, the motion of the crane tip is affected by vertical and rotational motions. Hence, it is necessary to compensate for the rotational motions of the offshore crane caused by the pitch and roll motions of the vessel, thereby enhancing the performance of the payload position control.

The actual parameters of the offshore crane are mainly approximated, which results in parametric uncertainties and disturbances. Therefore, the controller can lead to the instability of the system if it is designed without considering the robustness criterion. In $[8,9]$ for instance, the classical feedback linearization technique was used to linearize the system dynamics [10]. This method eliminates the nonlinear elements, and for systems with uncertain nonlinearities, this elimination presents several disadvantages. Thus, the close-loop system controlled with the IOLC turned out not to be robust [11-13].

Therefore, in this paper, we discuss the control system design of the payload position control to improve the control performance and to guarantee the robustness of the closedloop system. The dynamic modeling of the offshore crane was conducted on a 4 degrees-offreedom (DOF) model reduced from an 11-DOF model. In this dynamic model, the vertical motion as well as the rotational motion of the offshore crane is considered as representative of the offshore crane dynamics, but it is more detailed compared to the studies mentioned above. The main purpose of any control system is to design a controller that provides robustness and helps to cope with the uncertainties. To achieve these objectives, the proposed controller is designed based on the uniformly ultimately boundedness (UUB) combined with the IOLC control system (UUB+IOLC); derived from the energy-based Lyapunov function and satisfying the UUB condition. To evaluate the performance of the proposed controller, we introduce an ISMC and compare its response with the UUB+IOLC. The ISMC has been developed and applied in various applications [14-18] as a solution to the robustness and performance issues of the conventional sliding mode controller (SMC). To validate the efficiency of the proposed controller, two sets of experiments were conducted on the pilot model; the first is an experiment with the nominal system and the second is with an uncertain system. Subsequently, an experimental comparison study between the aforementioned controllers was conducted.

The structure of this paper is as follows: Section 2 presents the dynamic modeling of the offshore crane. In Section 3, the design of IOLC, UUB+IOLC, and ISMC control systems are described in detail. Then, the experimental results are presented in Section 4. Finally, the conclusions of this study are summarized in Section 5. 


\section{System Modeling}

The typical offshore crane has 11-DOF in total [19]. The vessel has 6-DOF and the crane has 5-DOF itself (luff and slew angle of the boom, 2-D swing motion of a payload, and cable length). Considering actual operating conditions, we can reduce the system's degrees of freedom from 11 to 4-DOF with the following simplifying assumptions

- The surge, sway, and yaw motions are ignored since they are handled by a dynamic positioning system (DPS).

- The luff and slew angles are not controlled with the payload control system and their values are known and considered as constants.

- The crane base and the crane tip are aligned with one of the horizontal axes of the b-frame.

According to the second and third assumptions, the swing motion of the payload is considered a 1-D motion. That is, the payload motion is a movement in the vertical plane. Therefore, the vessel heave and roll (or pitch) motions, as well as the cable length, are parameters taken into account. In this paper, in particular, we consider that the crane base and the crane tip are aligned with the $y_{b}$ axis. The schematic of the 4-DOF offshore crane system is illustrated in Figure 1. The position of the system is defined in the northeast-down coordinate frame ( $\mathrm{n}$-frame, $o_{n} x_{n} y_{n} z_{n}$ ), and the angular and linear velocities are defined in the body-fixed frame (b-frame, $o_{b} x_{b} y_{b} z_{b}$ ). Additionally, it is assumed that the center of mass of the offshore crane coincides with the origin of the b-frame. The offshore crane is considered a rigid body. The rope-suspended payload is approximated by a mass-spring-damper system with the payload mass $m$, the spring constant $k_{r}$, the damping constant $c_{r}$, and the rope length variation $\delta$. However, the damping force of the rope is neglected since the dominant damping force of the payload dynamics is the hydrodynamic force [20]. The payload position control system is actuated by a winch. The winch dynamics model is approximated by a second-order differential equation with the angle of rotation $\theta$ and $r$ as the radius of the drum.

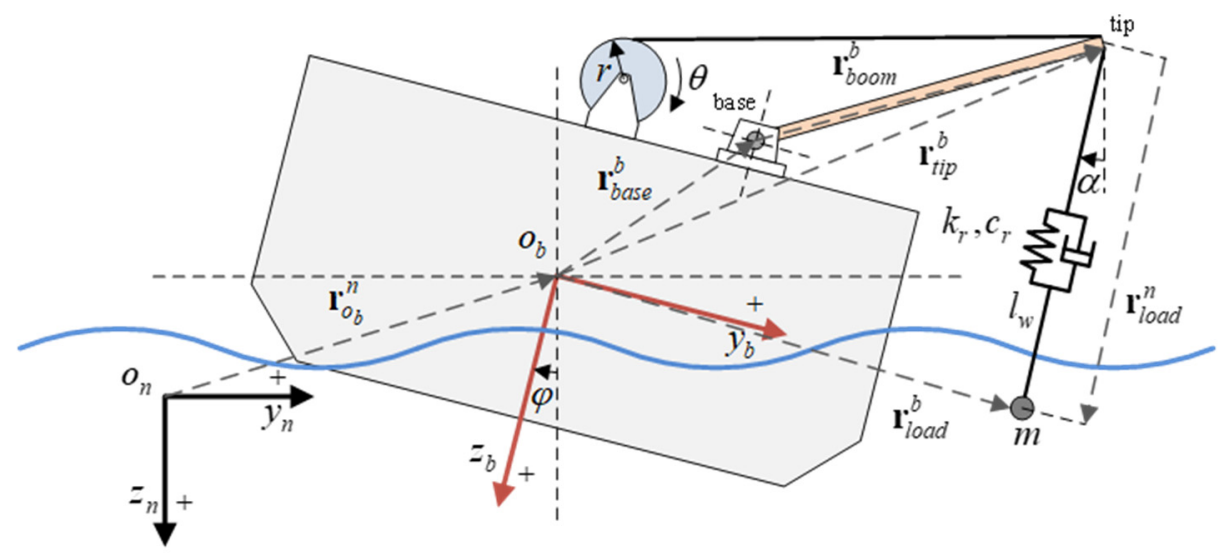

Figure 1. Schematic of offshore crane system and the reference frame. The offshore crane stays afloat in the presence of perturbations. The dashed arrows indicate the location of relevant points in the system's frames.

The vector from the origin $o_{b}$ to the crane tip is expressed in the b-frame as $\mathbf{r}_{\text {tip }}^{b}=$ $\left[\begin{array}{lll}0 & y_{\text {tip }}^{b} & z_{\text {tip }}^{b}\end{array}\right]^{T}$. The rotation matrix between the $\mathrm{n}$-frame and the $\mathrm{b}$-frame is given as

$$
\mathbf{R}_{b}^{n}=\mathbf{R}_{x, \varphi}=\left[\begin{array}{ccc}
1 & 0 & 0 \\
0 & \cos \varphi & -\sin \varphi \\
0 & \sin \varphi & \cos \varphi
\end{array}\right]
$$


It is assumed that the vector from $o_{n}$ to $o_{b}$ is defined as $\mathbf{r}_{o_{b}}^{n}=\left[\begin{array}{lll}0 & 0 & Z_{\text {heave }}\end{array}\right]^{T}$. Then, the position of the crane tip expressed in the $\mathrm{n}$-frame can be calculated as

$$
\begin{aligned}
\mathbf{p}_{\text {tip }}^{n} & =\mathbf{r}_{o_{b}}^{n}+\mathbf{R}_{b}^{n} \mathbf{r}_{\text {tip }}^{b} \\
& =\mathbf{r}_{o_{b}}^{n}+\mathbf{r}_{\text {tip }}^{n} \\
& =\left[\begin{array}{c}
0 \\
y_{\text {tip }}^{b} \cos \varphi-z_{\text {tip }}^{b} \sin \varphi \\
z_{\text {tip }}^{b} \cos \varphi+y_{\text {tip }}^{b} \sin \varphi+Z_{\text {heave }}
\end{array}\right]
\end{aligned}
$$

In order to derive the position of the payload, we define the vector from the crane tip to the payload as:

$$
\mathbf{r}_{\text {load }}^{n}=\left[\begin{array}{lll}
0 & -\left(l_{w}+\delta\right) \sin \alpha & \left(l_{w}+\delta\right) \cos \alpha
\end{array}\right]^{T}
$$

where $l_{w}=l_{w}(0)+r \theta$ is the rope length. Using Equations (2) and (3), we determine the payload position vector expressed in the $\mathrm{n}$-frame as

$$
\begin{aligned}
\mathbf{p}_{\text {load }}^{n} & =\mathbf{p}_{\text {tip }}^{n}+\mathbf{r}_{\text {load }}^{n} \\
& =\left[\begin{array}{c}
0 \\
-\left(l_{w w}+\delta\right) \sin \alpha+y_{\text {tip }}^{b} \cos \varphi-z_{\text {tip }}^{b} \sin \varphi \\
\left(l_{w}+\delta\right) \cos \alpha+z_{\text {tip }}^{b} \cos \varphi+y_{\text {tip }}^{b} \sin \varphi+Z_{\text {heave }}
\end{array}\right]
\end{aligned}
$$

Thus, we can calculate the velocity and acceleration of the crane tip and the payload easily with a time derivative of (2) and (3).

Based on Equations (2) and (4), the kinetic energy $T$ and the potential energy $U$ of the offshore crane system are given as

$$
\begin{aligned}
& T=\frac{1}{2}\left(m_{\text {tip }} \dot{\mathbf{p}}_{\text {tip }}^{n}{ }^{T} \dot{\mathbf{p}}_{\text {tip }}^{n}+m \dot{\mathbf{p}}_{\text {load }}^{n}{ }^{T} \dot{\mathbf{p}}_{\text {load }}^{n}\right) \\
& U=-g\left(m_{\text {tip }} \mathbf{p}_{\text {tip }}^{n}+m \mathbf{p}_{\text {load }}^{n}\right)+\frac{1}{2} k_{r} \delta^{2}
\end{aligned}
$$

where $m_{t i p}$ is the equivalent mass of the crane tip and $g$ is the gravitational acceleration. We define the state $\mathbf{q}=\left[\begin{array}{ll}q_{1} & q_{2}\end{array}\right]^{T}=\left[\begin{array}{ll}\delta & \alpha\end{array}\right]^{T}$ as the generalized coordinates and $f_{i}$ as the generalized forces represented as follows

$$
\begin{aligned}
& f_{1}=f_{B} \cos \alpha+f_{h}\left(\mathrm{p}_{\text {load }, y}^{n}\right) \sin \alpha+f_{h}\left(\mathrm{p}_{\text {load }, z}^{n}\right) \cos \alpha \\
& f_{2}=f_{B} \sin \alpha+f_{h}\left(\mathrm{p}_{\text {load }, y}^{n}\right) \cos \alpha+f_{h}\left(\mathrm{p}_{\text {load }, z}^{n}\right) \sin \alpha
\end{aligned}
$$

where Equations (7) and (8) are the hydrodynamic forces acting on the submerged payload. $f_{B}$ is the buoyance force and $f_{h}$ is the added mass and damping force-expressed in terms of the payload velocity and acceleration. Figure 2 shows the schematic diagram of the payload rotating about the crane tip. The resulting Lagrange equation is given as

$$
\frac{d}{d t}\left(\frac{\partial T}{\partial \dot{q}_{i}}\right)-\frac{\partial T}{\partial q_{i}}+\frac{\partial U}{\partial q_{i}}=f_{i}, \quad(i=1,2)
$$

Then the nonlinear motion equations are obtained as

$$
\begin{aligned}
f_{1}= & \delta k_{\text {eq }}+\ddot{\delta} m+\ddot{l}_{w w} m-\delta \dot{\alpha}^{2} m+\ddot{Z}_{\text {heave }} m \cos \alpha-g m \cos \alpha-\dot{\alpha}^{2} l_{w} m+\dot{\varphi}^{2} m y_{\text {tip }}^{b} \sin (\alpha-\varphi) \\
& +\ddot{\varphi} m y_{\text {tip }}^{b} \cos (\alpha-\varphi)+\ddot{\varphi} m z_{\text {tip }}^{b} \sin (\alpha-\varphi)-\dot{\varphi}^{2} m z_{\text {tip }}^{b} \cos (\alpha-\varphi)
\end{aligned}
$$




$$
\begin{aligned}
f_{2}= & m\left(\delta+l_{w}\right)^{2} \ddot{\alpha}+2 \dot{\alpha} \dot{\delta} l_{w} m+2 \dot{\alpha} \dot{l}_{w w} l_{w} m-\delta \ddot{Z}_{\text {heave }} m \alpha-\ddot{Z}_{\text {heave }} l_{w w} m \sin \alpha+\delta g m \sin \alpha \\
& +g l_{w} m \sin \alpha+2 \delta \dot{\alpha} \dot{\delta} m+2 \delta \dot{\alpha} \dot{l}_{w w} m+\delta \ddot{\varphi} m z_{\text {tip }}^{b} \cos (\alpha-\varphi)+\ddot{\varphi} l_{w w} m z_{\text {tip }}^{b} \cos (\alpha-\varphi) \\
& -\delta \ddot{\varphi} m y_{\text {tip }}^{b} \sin (\alpha-\varphi)-\ddot{\varphi} l_{w} m y_{\text {tip }}^{b} \sin (\alpha-\varphi)+\delta \dot{\varphi}^{2} m y_{\text {tip }}^{b} \cos (\alpha-\varphi) \\
& +\dot{\varphi}^{2} l_{w} m y_{\text {tip }}^{b} \cos (\alpha-\varphi)+\delta \dot{\varphi}^{2} m z_{\text {tip }}^{b} \sin (\alpha-\varphi)+\dot{\varphi}^{2} l_{w} m z_{\text {tip }}^{b} \sin (\alpha-\varphi)
\end{aligned}
$$

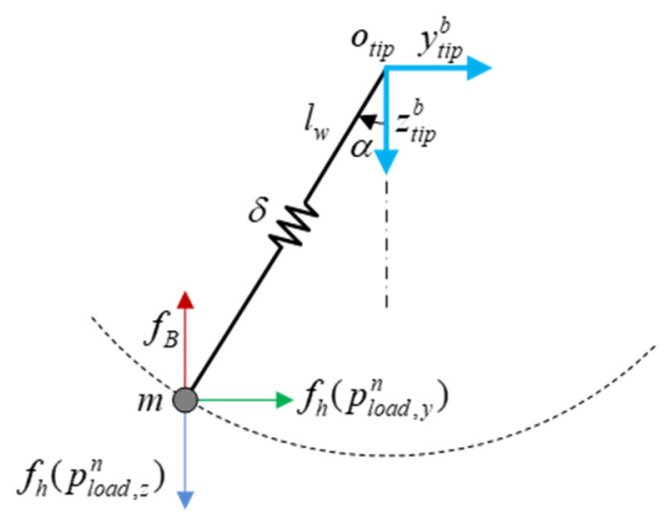

Figure 2. Force diagram of the submerged payload.

Based on the derived Equations (10) and (11), the offshore crane is highly nonlinear and coupled with the states $\alpha$ and $\delta$. In real-life applications, particularly subsea installations, the payload swing motion suppression is not of significant concern in case of tackling the payload positioning control problem. Therefore, decoupling the swing motion from the vertical dynamics is required to design a robust controller to cope with uncertainties.

In order to decouple the nonlinear equation, a linear approximation is formulated around the operating point where $l_{w} \approx l_{w}(0)$, thus $\dot{l}_{w} \approx r \dot{\theta}$, and $\ddot{l}_{w} \approx r \ddot{\theta}$. Besides, the small-angle approximation implies that $\sin \alpha \approx \alpha, \cos \varphi \approx \varphi$, and $\cos \alpha=\cos \varphi \approx 1$. Thereafter, we can get a decoupled linear model as the following

$$
\begin{gathered}
\delta k_{r}+\ddot{\delta} m+\ddot{l}_{w} m+\ddot{Z}_{\text {heave }} m-g m+\ddot{\varphi} m y_{\text {tip }}^{b}=f_{B}+f_{h}\left(\mathrm{p}_{\text {load }, z}^{n}\right) \\
m l_{w}^{2}(0)+g l_{w}(0) m \ddot{\alpha}+\ddot{\varphi} l_{w}(0) m z_{\text {tip }}^{b}=f_{h}\left(\mathrm{p}_{\text {load }, y}^{n}\right)
\end{gathered}
$$

where $f_{B}$ and $f_{h}$ are defined as $[3,6,20,21]$

$$
\begin{gathered}
f_{B}=-\rho_{w} g V_{p} \\
f_{h}(X)=-\rho_{w} V_{p} \ddot{X}-m_{a} \ddot{X}-\frac{1}{2} \rho_{w} C_{D} A_{p} \dot{X}|\dot{X}|
\end{gathered}
$$

where $\rho_{w}$ is the density of water, $m_{a}$ is referred to as the added mass from submersion given as $m_{a}=\rho_{w} V_{p} C_{a}$ with $C_{a}$ as the coefficient of the added mass determined based on the shape of the payload. Besides, $C_{D}$ is the drag coefficient and $A_{p}$ is the payload's nominal cross-section in the vertical direction.

The advantage of this method is that the design of a control system is more convenient and it gives more insight into the dynamics of the system. From Equations (12) and (13), one concludes that the vertical dynamics and the dynamics of the horizontal motion are the dominant components of the system representation. However, according to [22], eliminating the dynamics of the horizontal motion does not affect the performance of the simplified system dynamics. Therefore, in this paper, the vertical dynamics in Equation (12) of the decoupled model is used to design the payload position control system for the offshore cranes. Combining Equations (12), (14), and (15), the offshore crane model is obtained as

$$
\ddot{\delta} m_{p}=-r \ddot{\theta} m_{p}-\delta k_{r}+F_{g}-F_{b}-\frac{1}{2} \rho_{w} C_{D} A_{p} \dot{\mathrm{p}}_{\text {load }, z}^{n}\left|\dot{\mathrm{p}}_{\text {load }, z}^{n}\right|-m_{p}\left(\ddot{Z}_{\text {heave }}+y_{\text {tip }}^{b} \ddot{\varphi}\right)
$$


where $m_{p}=m+m_{a}+\rho_{w} V_{p}, F_{g}=g m$, and $F_{b}=\rho_{w} g V_{p}$. The velocity of the payload in the $z_{n}$-axis is given as $\dot{p}_{\text {load }, z}^{n}=r \dot{\theta}+\dot{\delta}+y_{\text {tip }}^{b} \dot{\varphi}+\dot{Z}_{\text {heave }}$. The rope spring constant follows Hooke's law and depends on the rope length, its expression is as the following

$$
k_{r}=\frac{E A}{l_{w}}
$$

where $E$ and $A$ are the modulus of elasticity and the cross-section area of the rope, respectively. As already mentioned, the dynamics of the winch is approximated by a second-order differential equation, which is expressed as

$$
J_{w} \ddot{\theta}+C_{w} \dot{\theta}+K_{w} \theta=T_{w} u_{w}
$$

where $J_{w}$ is the moment of inertia, $C_{w}$ is the damping constant, $K_{w}$ is the stiffness constant, $T_{w}$ is the torque, and $u_{w}$ is the control input to the winch.

\section{Control System Design}

\subsection{Control Strategy}

The objective of a control system is trajectory tracking and position keeping of the payload under uncertainties, mainly wave disturbance and parametric uncertainties. In other words, the control objective is for the position of the payload $\mathrm{p}_{\text {load, },}^{n}$ to converge to the desired position $\mathrm{p}_{r e f}^{n}$ generated by the operator. That is, the payload position expressed in the $\mathrm{n}$-frame satisfies the following condition

$$
\mathrm{p}_{\text {load }, z}^{n}=l_{w}(0)+r \theta+\delta+z_{\text {tip }}^{b}+y_{\text {tip }}^{b} \varphi+Z_{\text {heave }} \Rightarrow \mathrm{p}_{r e f}^{n}
$$

Additionally, the tension variations in the rope need to be minimized to prevent rope rupture. This control objective should be achieved despite the motion of the host vessel and variations of the rope.

In order to achieve this control objective, we assume that the motion of the vessel $\left(Z_{\text {heave }}, \varphi\right)$ is measured by an inertial measurement unit (IMU). In $[8,9,23]$, a prediction algorithm for the vertical motion was introduced to generate the trajectory in real-time $[8,23]$ and to overcome delays resulting from data processing of the IMU signals and the trajectory generation [9]. However, this paper focuses on improving the performance of the payload positioning control for an offshore crane without a prediction algorithm.

\subsection{Input-Output Linearization Technique Based Controller (IOLC) Design}

To design the IOLC, the dynamic model of the system should be transformed into the state-space representation. With the state vector defined as

$$
\begin{aligned}
\mathbf{x} & =\left[\begin{array}{llllll}
x_{1} & x_{2} & x_{3} & x_{4} & x_{5} & x_{6}
\end{array}\right]^{T} \\
& =\left[\begin{array}{llllll}
\delta & \dot{\delta} & \theta & \dot{\theta} & \lambda & \dot{\lambda}
\end{array}\right]^{T}
\end{aligned}
$$

The state-space model of the offshore crane with the disturbance expressed in terms of the second-derivative of the vessel's motion is obtained as

$$
\begin{aligned}
& \dot{\mathbf{x}}=\mathbf{f}(\mathbf{x})+\mathbf{g} u+\mathbf{w} d \\
& y=h(\mathbf{x})
\end{aligned}
$$




$$
\begin{aligned}
& \mathbf{f}(\mathbf{x})=\left[\begin{array}{c}
x_{2} \\
-\frac{k_{r}}{m_{p}} x_{1}+\frac{r_{w} K_{w}}{J_{w}} x_{3}+\frac{r C_{w}}{J_{w w}} x_{4}-\frac{1}{2 m_{p}} \rho_{w} C_{d} A_{p}\left(x_{2}+r x_{4}+x_{6}\right)\left|x_{2}+r x_{4}+x_{6}\right|+\frac{F_{g}-F_{b}}{m_{p}} \\
x_{4} \\
-\frac{K_{w}}{J_{w}} x_{3}-\frac{C_{w}}{J_{w}} x_{4} \\
x_{6} \\
0
\end{array}\right] \\
& \mathbf{g}=\left[\begin{array}{cccccc}
0 & -\frac{r T_{w}}{J_{w}} & 0 & \frac{T_{w}}{J_{w}} & 0 & 0
\end{array}\right]^{T} \\
& \begin{array}{c}
\mathbf{w}=\left[\begin{array}{cccccc}
0 & -1 & 0 & 0 & 0 & 1
\end{array}\right]^{T} \\
d=\ddot{Z}_{\text {heave }}+\ddot{\varphi} y_{\text {tip }}^{b}
\end{array}
\end{aligned}
$$

The output function is defined as $h(\mathbf{x})=-x_{1}+r x_{3}$. The control objective of the IOLC is for the output $h(\mathbf{x})$ to track the reference signal regardless of the disturbance. Thus, to design the control system, the relative degree of the system $r_{s}$ and that of the disturbance $r_{w}$ need to be determined to fulfill the following conditions [10]

$$
\begin{aligned}
& L_{g} L_{f}^{i} h(\mathbf{x})=0 \quad 0 \leq i<r_{s}-1 \\
& L_{g} L_{f}^{r_{s}-1} h(\mathbf{x}) \neq 0 \\
& L_{w} L_{f}^{k} h(\mathbf{x})=0 \quad 0 \leq k<r_{w}-1 \\
& L_{w} L_{f}^{r_{w w}-1} h(\mathbf{x}) \neq 0
\end{aligned}
$$

where $L_{(\cdot)}^{i}(\circ)$ is a scalar function that represents the $i$ th-order Lie derivative of $(\circ)$ with respect to $(\bullet)$. Based on Equations (22) and (23), we conclude that $r_{s}=2$ and $r_{w}=2$. Therefore, it is possible to employ the disturbance decoupling, since the relative degree of the system is greater than or equal to the relative degree of the disturbance, and the disturbance is measurable [10]. Then, we can decouple the disturbance from the controlled output with the disturbance decoupling control input. The resulting expression of the IOLC is as follows

$$
u_{w}=u_{I O}+u_{d d}
$$

where $u_{I O}$ is the input-output linearization control input and $u_{d d}$ is the decoupled disturbance control input defined as

$$
\begin{aligned}
& u_{I O}=\frac{-L_{f}^{2} h(\mathbf{x})+v}{L_{g} L_{f} h(\mathbf{x})} \\
& u_{d d}=\frac{-L_{p} L_{f} h(\mathbf{x}) d}{L_{g} L_{f} h(\mathbf{x})}
\end{aligned}
$$

where $v$ is the artificial input that yields a locally asymptotically stable closed-loop system with the output error $\zeta=r\left(\theta_{d}-\theta\right)+\delta$, and it is expressed as follows

$$
v=r \ddot{\theta}_{d}+k_{1} \dot{\zeta}+k_{2} \zeta
$$

For the system model in Equation (21), the IOLC (24) yields a simple relation $\ddot{y}=v$. Along with Equation (27), we obtain

$$
\ddot{\zeta}+k_{1} \dot{\zeta}+k_{2} \zeta=0
$$

The coefficients $k_{i}$ are state feedback gains. They are chosen to stabilize the closed-loop system which should be designed such that the polynomial (28) has its roots strictly in the left-half plane. Therefore, the local asymptotic stability of the closed-loop system is guaran- 
teed with the controller in Equation (24). To design the coefficients $k_{i}$, the linear quadratic regulator (LQR) control technique is used with the following controllable canonical form

$$
\begin{aligned}
& {\left[\begin{array}{l}
\dot{\zeta} \\
\ddot{\zeta}
\end{array}\right]=\left[\begin{array}{ll}
0 & 1 \\
0 & 0
\end{array}\right]\left[\begin{array}{l}
\zeta \\
\dot{\zeta}
\end{array}\right]+\left[\begin{array}{l}
0 \\
1
\end{array}\right] u_{z}} \\
& u_{z}=-\left[\begin{array}{ll}
k_{2} & k_{1}
\end{array}\right]\left[\begin{array}{l}
\zeta \\
\dot{\zeta}
\end{array}\right]
\end{aligned}
$$

And the performance index is given as

$$
J=\int_{0}^{\infty}\left(\mathbf{z}_{1}^{T} \mathbf{Q} \mathbf{z}_{1}+R u_{z}{ }^{2}\right) d t
$$

where the state vector is chosen as $\mathbf{z}_{1}=\left[\begin{array}{cc}\zeta & \dot{\zeta}\end{array}\right]^{T}, \mathbf{Q}=\operatorname{diag}\left(Q_{1}, Q_{2}\right)$ is a positive definite matrix, and $R$ is a positive constant.

\subsection{Uniformly Ultimately Bounded Controller (UUB+IOLC) Design}

In this section, we design the control system based on the proposed control process studied previously in $[24,25]$. A control system is designed with the resulting closed-loop system of the IOLC control scheme. The control input is designed to ensure the uniformly ultimately boundedness of the solutions of the system. To design the control system, we introduce the definition in Equation (31) that conditions the vector $\mathbf{z}$ to satisfy the UUB condition with $\beta$ as the ultimate bound

$$
\left\|\mathbf{z}\left(t_{0}\right)\right\| \leq \alpha \Rightarrow\|\mathbf{z}(t)\| \leq \beta, \quad \forall t \geq t_{0}+T
$$

where $\mathbf{z}=\left[\begin{array}{llll}\zeta & \dot{\zeta} & \delta & \dot{\delta}\end{array}\right]^{T}$ and $\alpha$ is a positive constant satisfying $0<\alpha<\beta$ and $T>0$. In order words, the controlled output $\zeta$, the rope variation $\delta$, and their time derivatives are bounded for all $t \geq 0$. To achieve this control objective, a new control input $u_{w 2}$ derived from the energy-based Lyapunov function is introduced as

$$
u_{w}=u_{w 1}+u_{w 2}
$$

where $u_{w 1}=u_{I O}+u_{d d}$, and for the sake of notational simplicity, Equation (24) is represented as

$$
u_{w_{1}}=u_{I O}+u_{d d}=\frac{-\Pi_{1}-D+v}{\gamma_{1}}
$$

Substituting Equations (32) and (33) into the second-order derivative of the controlled output, the dynamic model can be represented as

$$
\begin{aligned}
\dot{\mathbf{z}} & =\mathbf{f}\left(\mathbf{z}, u_{w 1}, u_{w 22}\right) \\
\mathbf{f}\left(\mathbf{z}, u_{w 1}, u_{w 2}\right) & =\left[\begin{array}{c}
\dot{\zeta} \\
-k_{1} \dot{\zeta}-k_{2} \zeta-\gamma_{1} u_{w 2} \\
\dot{\delta} \\
\Pi_{2}+\gamma_{2} u_{w 1}+\gamma_{2} u_{w 2}
\end{array}\right]
\end{aligned}
$$

where $\gamma_{1}=2 r T_{w} / J_{w}, \gamma_{2}=-r T_{w} / J_{w}$ and $\Pi_{2}$ represents the remainder term of Equation (16) except the control input term. In order to design the control input $u_{w 2}$, while satisfying the UUB conditions, the lower and upper bound need to be determined. Therefore, we introduce the following Lyapunov candidate

$$
V=\frac{1}{2} \mathbf{z}^{T} \mathbf{M z}+\Psi(\mathbf{z})
$$


where,

$$
\mathbf{M}=\left[\begin{array}{ccccc}
\sigma k_{2} & \sigma c_{1} & & 0_{2 \times 2} \\
\sigma c_{1} & \sigma & & k_{3} & c_{2} \\
0_{2 \times 2} & & c_{2} & 1
\end{array}\right]
$$

and $\left(\sigma, k_{3}, c_{1}, c_{2}\right)>0$ are the controller gains. In order to ensure the positive definiteness and derive the bounded Lyapunov function in Equation (35), it is assumed that $\Psi(\mathbf{z})$ satisfies the following condition

$$
\frac{k_{3}^{*}}{2} \delta^{2} \leq \frac{1}{2} k_{3} \delta^{2}+\Psi(\mathbf{z}), \quad \Psi(0)=0
$$

Then, we can determine the lower and upper bounds $\alpha_{1}(\mathbf{z})$ and $\alpha_{2}(\mathbf{z})$, respectively, as follows

$$
\begin{gathered}
\frac{1}{2} \mathbf{z}^{T} \mathbf{M}^{*} \mathbf{z} \leq V \leq \frac{1}{2} \mathbf{z}^{T} \mathbf{M z}+\Psi(\mathbf{z}) \\
\mathbf{M}^{*}=\left[\begin{array}{cccc}
\sigma k_{2} & \sigma c_{1} & & 0_{2 \times 2} \\
\sigma c_{1} & \sigma & k_{3}^{*} & c_{2} \\
0_{2 \times 2} & c_{2} & 1
\end{array}\right]
\end{gathered}
$$

And the positive definiteness of the Lyapunov function is ensured with the conditions $c_{1}<\sqrt{k_{2}}$ and $c_{2}<\sqrt{k_{3}^{*}}$. If the upper bound of the Lyapunov function time derivative-as far as Equation (37) is concerned-satisfies the condition $\dot{V} \leq-W(\mathbf{z})$ for $\forall\|\mathbf{z}\|>\omega$, where $W(\mathbf{z})$ is a continuous positive definite function, the solution of the system $\dot{\mathbf{z}}=\mathbf{f}\left(\mathbf{z}, u_{w 1}, u_{w 2}\right)$ in Equation (34) is UUB [26]. Based on this consideration, the control input $u_{w 2}$ can be derived easily by defining the function $\Psi(\mathbf{z})$ as the following

$$
\begin{gathered}
u_{w 2}=\left[\begin{array}{llll}
\xi \sigma c_{1} \gamma_{1} & \xi \sigma \gamma_{1} & -\left(\xi c_{2}+k_{3}\right) \gamma_{2} & -\left(\xi+k_{4}\right) \gamma_{2}
\end{array}\right] \mathbf{z} \\
\Psi(\mathbf{z})=-\frac{1}{2} k_{3} \delta^{2}\left(1-\gamma_{2}^{2}\right)
\end{gathered}
$$

where $\xi$ and $k_{4}$ are strictly positive constants. Along with Equations (36) and (39), the positive definiteness of the Lyapunov function is guaranteed with the following condition $k_{3}^{*} \leq k_{3} \gamma_{2}{ }^{2}$, that is, $c_{2}<\left|\gamma_{2}\right| \sqrt{k_{3}}$.

\subsection{Integral Sliding Mode Controller (ISMC) Design}

As above-mentioned, the integral sliding mode control system is introduced to compare the control performance with the proposed controller. The sliding mode controller is one of the most preferred control techniques to cope with parametric uncertainties and external disturbances. Let the coupled integral sliding surface be as follows

$$
S=g_{1} \dot{e}_{\theta}+g_{2} e_{\theta}+\int_{0}^{t}\left(g_{3} e_{\theta}(\tau)+g_{4} \delta(\tau)\right) d \tau+g_{5} \delta-S_{t=0}
$$

where $e_{\theta}=\theta_{d}-\theta$ with $\theta_{d}$ is the desired value of $\theta$, and $g_{1}, g_{2}, g_{3}, g_{4}$, and $g_{5}$ are positive constants. By adding the constant term $S_{t=0}$, the sliding surface satisfies $S(t)=0$ at $t=0$. Therefore, the controlled system is attracted to a sliding layer without the reaching phase. And the only necessary condition to eliminate the reaching phase is that the motion at the beginning should be always measurable.

With the conventional Lyapunov function $V=(1 / 2) S^{2}$, we define the control law satisfying the condition $\dot{V} \leq 0$ as

$$
u_{w}=\frac{C_{w}}{T_{w}} \dot{\theta}+\frac{K_{w}}{T_{w}} \theta-\frac{J_{w}}{T_{w} g_{1}}\left(g_{2} \dot{e}_{\theta}+g_{3} e_{\theta}+g_{4} \delta+g_{5} \dot{\delta}+\beta \operatorname{sign}(S)\right)
$$


where $\beta>\left|g_{1}\right|\left|\ddot{\theta}_{d}\right|_{\max }+g_{6}$ with $g_{6}$ is a strictly positive constant. The uniform continuity of $\dot{V}$ can be shown easily by proving the positive definiteness of the second derivative of the Lyapunov function expressed as the following

$$
\begin{aligned}
\ddot{V} & =-\frac{\beta}{|S|} S \dot{S} \\
& =-\frac{\beta}{|S|}(-\Pi|S|) \\
& =\beta^{2}
\end{aligned}
$$

Therefore, with the application of Barbalat's lemma [27], we determine that $\dot{V} \rightarrow 0$ as $t \rightarrow \infty$. That is, $V$ approaches a finite value, and with the proper choice of $S_{t=0}$, the sliding surface converges to zero as $t \rightarrow \infty$.

However, since the sliding surface is coupled, the convergence of the states $e_{\theta}$ and $\delta$ to their corresponding equilibrium points cannot be ensured simultaneously, especially with the presence of the uncertainties such as hydrodynamic parameter variation or disturbances. In order to overcome this problem, Tho et al. $[15,16,28]$ derived the algebraic inequality of the controller gains using a robust stability analysis with Lyapunov's linearization method.

Therefore, based on this method, the robust stability analysis of the offshore crane is conducted in this section. Assuming that the system remains on the sliding surface $S=0$ and $\dot{S}=0$, and with the state vector defined as $\mathbf{v}=\left[\begin{array}{llll}e_{\theta} & \dot{e}_{\theta} & \delta & \dot{\delta}\end{array}\right]^{T}$, the closed-loop system is thus represented as

$$
\mathbf{f}(\boldsymbol{v})=\left[\begin{array}{c}
\dot{\mathbf{v}}=\mathbf{f}(\mathbf{v}) \\
v_{2} \\
-g_{1}{ }^{-1}\left(g_{3} v_{1}+g_{2} v_{2}+g_{4} v_{3}+g_{5} v_{4}\right)-\ddot{\theta}_{d} \\
\zeta_{4} \\
-k_{r} m_{p}{ }^{-1} v_{3}-g_{1}{ }^{-1}\left(g_{3} v_{1}+g_{2} v_{2}+g_{4} v_{3}+g_{5} v_{4}\right)-F^{*}
\end{array}\right]
$$

where $F^{*}$ represents the remainder term of Equation (16) except the terms related to the state vector $\mathbf{v}$. If we consider that the system behavior remains in the vicinity of the equilibrium point, it can be assumed that $k_{r}$ is constant. Then the linearized model of Equation (43) is obtained as

$$
\dot{\mathbf{v}}=\mathbf{A v}
$$

where,

$$
\mathbf{A}=\left[\begin{array}{cccc}
0 & 1 & 0 & 0 \\
-g_{3} / g_{1} & -g_{2} / g_{1} & -g_{4} / g_{1} & -g_{5} / g_{1} \\
0 & 0 & 0 & 1 \\
-g_{3} / g_{1} & -g_{2} / g_{1} & -\left(g_{4} / g_{1}\right)-\left(k_{r} / m_{p}\right) & -g_{5} / g_{1}
\end{array}\right]
$$

Based on Lyapunov's linearization method, the sufficient conditions ensuring robust stability of the uncertain linear system are derived from the characteristic Equation of (44), which satisfies the Hurwitz stability criterion. Thus, the inequality conditions are as follows

$$
\begin{aligned}
& g_{1}, g_{2}, g_{3}, g_{4}, g_{5}>0 \\
& g_{2} g_{4}>g_{3} g_{5}
\end{aligned}
$$

As a result of the control input in Equation (41) and the conditions of Equation (45), all the controlled variables of the closed-loop system asymptotically converge to their desired values.

\section{Experiment and Results}

\subsection{Experimental Setup}

The experimental apparatus used for this study is illustrated in Figure 3. The ropesuspended payload is lifted and lowered using a winch system. The winch system consists of a DC motor, a gearbox, an encoder, and a motor driver. The encoder calculates the rope 
length and the load cell—suspended by the rope-measures the tension of the rope. On the other hand, a gyro sensor is used to measure the Euler angles. The detailed specifications of the experimental apparatus are listed in Table 1.

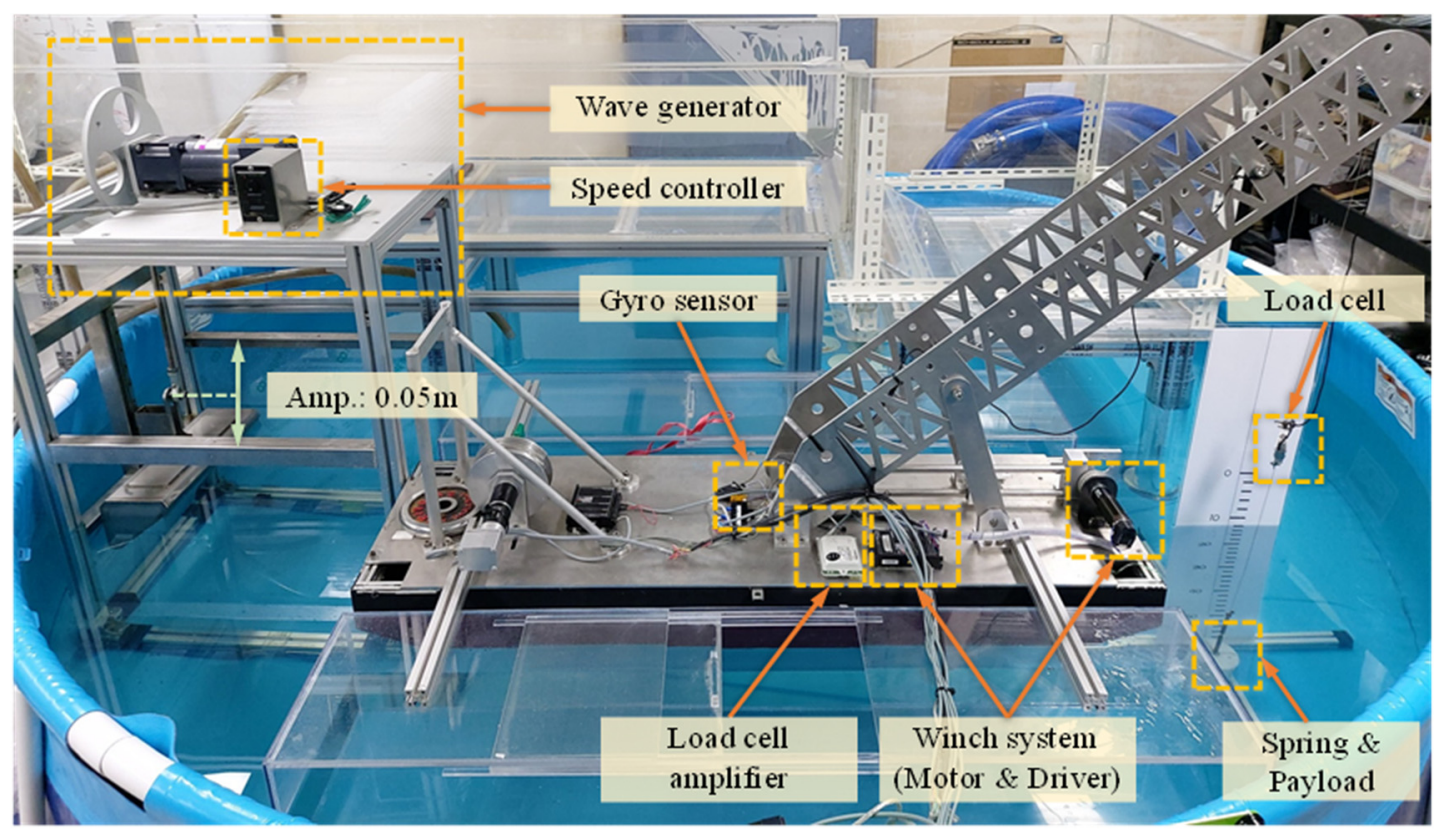

Figure 3. The experimental setup of the offshore crane pilot model that stays afloat in the basin. The wave generator is used to generate perturbations acting on the pilot model and positioned at the aft of the pilot vessel. The reciprocating displacement is $0.1 \mathrm{~m}$. The components of the experimental apparatus—sensors, actuators, and mechanical parts—are highlighted with dashed rectangles. The wave generator is positioned at the aft of the pilot vessel.

Table 1. Experimental apparatus specifications of the offshore crane model.

\begin{tabular}{|c|c|c|c|c|c|}
\hline Item & Parameter & Value & Item & Parameter & Value \\
\hline \multirow{7}{*}{$\begin{array}{l}\text { Winch } \\
\text { System }\end{array}$} & \multicolumn{2}{|c|}{$\begin{array}{l}\text { Motor: Maxon (334067) } \\
\text { Driver: ESCON 50/5 }\end{array}$} & \multirow{3}{*}{ Load cell } & \multicolumn{2}{|c|}{ CAS (CSBA-1LS) } \\
\hline & $\begin{array}{l}\text { Rated } \\
\text { voltage }\end{array}$ & $24 \mathrm{~V}$ & & Capacity & $1 \mathrm{kgf}$ \\
\hline & Rated power & $90 \mathrm{~W}$ & & Rated output & $\begin{array}{c}1.0 \pm 0.2 \\
\mathrm{mV} / \mathrm{V}\end{array}$ \\
\hline & $\begin{array}{l}\text { Rated torque } \\
\text { Rated speed }\end{array}$ & $\begin{array}{l}0.105 \mathrm{~N} \cdot \mathrm{m} \\
7750 \mathrm{rpm}\end{array}$ & \multirow{4}{*}{$\begin{array}{l}\text { Load cell } \\
\text { transducer } \\
\text { amplifier }\end{array}$} & \multicolumn{2}{|c|}{ CAS (LCT-II) } \\
\hline & Gear ratio & $28: 1$ & & Output & $0 \sim 5 \mathrm{~V}$ \\
\hline & Resolution & $500 \mathrm{ppr}$ & & Accuracy & $\pm 0.02 \%$ \\
\hline & Drum radius & $0.025 \mathrm{~m}$ & & Linearity & $\pm 0.02 \%$ \\
\hline \multirow{3}{*}{ DAQ } & \multicolumn{2}{|c|}{$\begin{array}{l}\text { National Instrument } \\
\text { (PCI-6259) }\end{array}$} & \multirow{3}{*}{ Gyro sensor } & \multicolumn{2}{|c|}{ NTRex (MW-AHRS) } \\
\hline & $\begin{array}{l}\text { ADC } \\
\text { resolution }\end{array}$ & 16 bits & & $\begin{array}{c}\text { Euler an- } \\
\text { gle'sresolution }\end{array}$ & $0.01 \mathrm{deg}$ \\
\hline & $\begin{array}{l}\text { Sample rate } \\
\text { (single chan.) }\end{array}$ & $1.25 \mathrm{MS} / \mathrm{s}$ & & Response time & $<1 \mathrm{~ms}$ \\
\hline \multirow{2}{*}{$\begin{array}{c}\text { Inserted } \\
\text { spring } \\
(1 \mathrm{EA})\end{array}$} & Mass & $0.004 \mathrm{~kg}$ & $\begin{array}{l}\text { Offshore } \\
\text { crane }\end{array}$ & $y_{\text {tip }}^{b}$ & $0.913 \mathrm{~m}$ \\
\hline & $\begin{array}{l}\text { Spring } \\
\text { constant }\end{array}$ & $130.8 \mathrm{~N} / \mathrm{m}$ & $\begin{array}{l}\text { Payload } \\
\text { (1EA) }\end{array}$ & Mass & $0.2 \mathrm{~kg}$ \\
\hline
\end{tabular}


Since the payload position and the rope length variations cannot be measured directly, the load motion estimation technique is applied, as described in [29]. The load motion estimation technique uses load cell data to measure rope tension.

The unknown parameters of the pilot model-the dynamics of actuators and the hydrodynamic coefficients of the payload - are identified experimentally. To start with, in order to identify the model of the actuator consisting of a DC motor and its driver, we set up the driver as an open-loop speed controller with ESCON Studio (Maxon Motor Co.). Then, we use the chirp signal as input with a frequency range from $0.1 \mathrm{~Hz}$ to $2 \mathrm{~Hz}$ and a varying amplitude of $1 \mathrm{~V}, 2 \mathrm{~V}$, and $3 \mathrm{~V}$. Using the data of the input signal in [V] and the output signal of the encoder in [deg], we can estimate the actuator's model with MATLAB identification toolbox. The mathematical representation of the actuator is presented as

$$
\ddot{\theta}+102.8 \dot{\theta}+0.1444 \theta=26371 u_{w}
$$

The payload used for the experiment of the nominal system is attached to the end of the rope, as shown in Figure 4. The weight of the added mass is $0.6 \mathrm{~kg}$ and that of the spring is at $0.012 \mathrm{~kg}$. The equivalent spring constant is $43.6 \mathrm{~N} / \mathrm{m}$. We assume that the mass of the rope is neglected since it is too small. Then, the hydrodynamic coefficients of the payload are identified by analyzing the difference between the dynamic response in the air and water. Thus, we obtain $C_{a}=0.4$ and $C_{D}=1$.

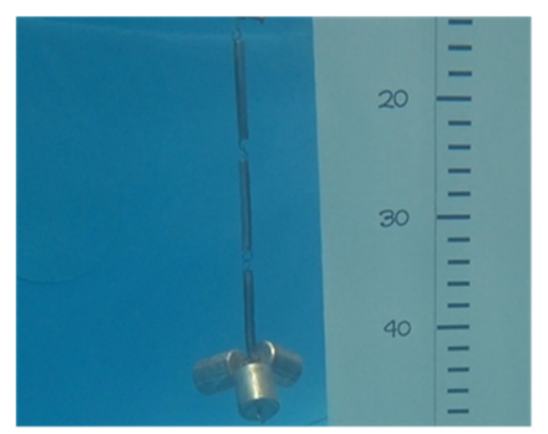

Figure 4. Picture of the payload used in the experiment.

The wave generator consists of a speed controller and an AC motor. The wave disturbance is introduced in four stages; $20 \%, 40 \%, 60 \%$, and $80 \%$ of the output power of the wave generator. The frequency of the produced wave disturbance is listed in Table 2.

Table 2. The frequency of the wave disturbance.

\begin{tabular}{ccccc}
\hline Output Power & $\mathbf{2 0 \%}$ & $\mathbf{4 0 \%}$ & $\mathbf{6 0 \%}$ & $\mathbf{8 0} \%$ \\
\hline Frequency $[\mathrm{Hz}]$ & 0.4778 & 0.8897 & 1.1494 & 1.5244 \\
\hline
\end{tabular}

The heave and roll motions of the pilot vessel are neglected. This is a suitable assumption since the wave encounter angle is $0 \mathrm{deg}$. In this case, the pitch motion is mainly induced by the wave disturbance. The fast Fourier transform (FFT) of the roll and pitch motion of the pilot vessel is shown in Figure 5. As shown in this figure, the amplitude of the roll motion, as well as the pitch motion, is so small as to be negligible when the output power is at $80 \%$. Therefore, the latter case is not going to be studied in the following experiments since it does not introduce any significant challenges.

The desired position of the payload $P_{r e f}^{n}$ is an alternation of a $0.2 \mathrm{~m}$ ascent for 3 seconds and a descent of $0.2 \mathrm{~m}$ after 20 seconds. In order to generate a sufficiently smooth desired position signal, we use the third-order Hermite interpolation with the MATLAB command 'pchipinterp'. The generated desired position of the payload is illustrated in Figure 6. However, in practice, when the output power of the wave generator is at $40 \%$, the amplitude of the desired position is set to be $0.1 \mathrm{~m}$ due to the basin depth limitations. 


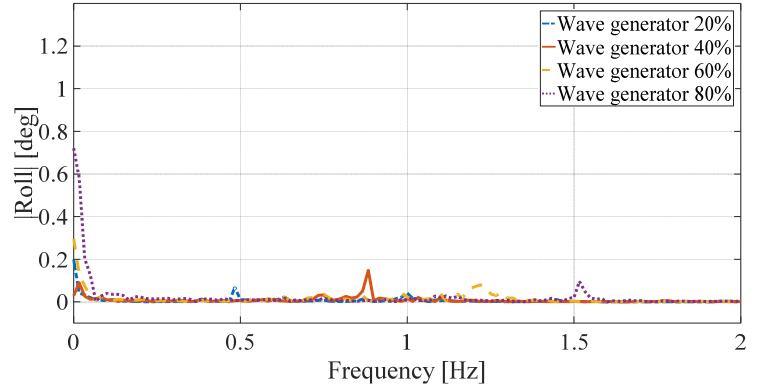

(a)

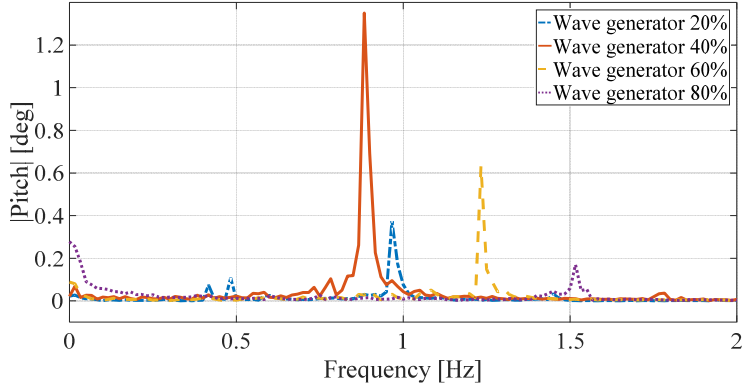

(b)

Figure 5. Fast Fourier transform (FFT) results of the pilot vessel's motion for each wave generator power capacity. The roll angle (a), and the pitch angle (b).

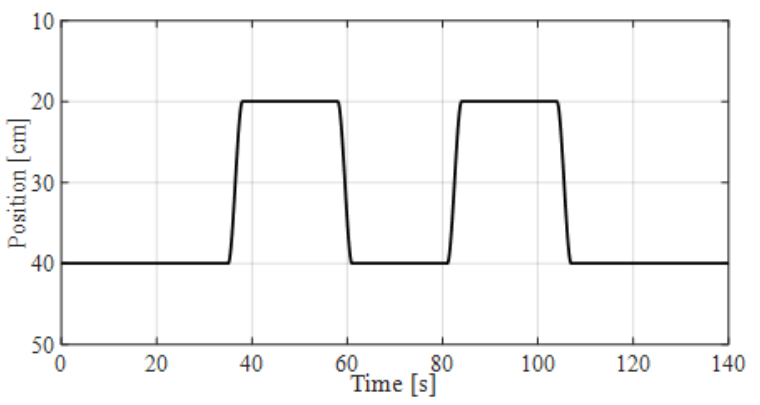

Figure 6. The desired position of the payload used in the experiment.

Using this experimental configuration, the controller gains are sufficiently tuned to obtain the best performance possible; their values are listed in Table 3.

Table 3. The controller gains used in the experiment.

\begin{tabular}{|c|c|}
\hline Controller & Gain \\
\hline IOLC & $\begin{array}{c}q_{1}=7000, q_{2}=300, R=0.02 \\
\rightarrow k_{1}=127.213, k_{2}=591.608\end{array}$ \\
\hline ISMC & $\begin{array}{l}k_{1}=127.213, k_{2}=591.608 \\
\sigma=0.0005, k_{3}=0.1, k_{4}=0.001 \\
c_{1}=6.49158, c_{2}=2.083, \varepsilon=0.0005\end{array}$ \\
\hline UUB+IOLC & $\begin{array}{l}g_{1}=0.01, g_{2}=1, g_{3}=40, g_{4}=700, \\
g_{5}=50, g_{6}=0.44\left(\left|\ddot{\theta}_{d}\right|_{\max }=6, \beta=0.5\right)\end{array}$ \\
\hline
\end{tabular}

To evaluate the performance of each controller, we introduce the integral of absolute error (IAE),

$$
J=\int_{0}^{\infty}\left|e_{P}(\tau)\right| d \tau
$$

Where $e_{p}=P_{r e f}^{n}-P_{\text {load }, z}^{n}$. The relative value to the uncompensated case for each wave disturbance case $\left(J_{\text {relative }}=\int_{0}^{\infty}\left|e_{P}(\tau)\right| d \tau / J_{\text {uncomp. }}\right)$ are also calculated. In this paper, the uncompensated case is when the control system only feedbacks the encoder signal to track the desired position of the payload using a PID controller. This method provides an intuitive evaluation of the performance of a control system.

We have two experimental scenarios to validate the control performance; the first is conducted with the nominal system and the second is conducted with an uncertain system. The results of each experiment are introduced in Sections 4.2 and 4.3, respectively. 


\subsection{Experimental Result with the Nominal System}

In the following experiments, the controller is switched off during the first 15 seconds. Thereafter, the controller is activated. The performance index results of each experiment are listed in Table 4. In these results, only the data sets obtained when the controller is switched on are included. As depicted in this table, in the case of UUB+IOLC the performance index has the smallest value for all the wave disturbance cases. On the other hand, IOLC has the largest values.

Table 4. Performance index result of the experiment of each wave condition.

\begin{tabular}{cccc}
\hline Output Power & $\mathbf{2 0 \%}$ & $\mathbf{4 0 \%}$ & $\mathbf{6 0 \%}$ \\
\hline Uncompensated $^{1}()^{2}$ & $160.1272(1)$ & $452.0344(1)$ & $355.5983(1)$ \\
IOLC & $102.4312(0.64)$ & $326.7183(0.72)$ & $137.3719(0.39)$ \\
ISMC & $64.5909(0.40)$ & $250.9576(0.56)$ & $98.21(0.28)$ \\
UUB+IOLC & $55.023(0.34)$ & $190.8782(0.42)$ & $85.2664(0.24)$ \\
\hline
\end{tabular}

${ }^{1}$ Value of integral of absolute error $(J) .{ }^{2}$ Relative value of performance index to the uncompensated case (Jelative).

Note that only the results when the power output is at $40 \%$ will be introduced, as illustrated in Figures 7 and 8. Figure 7 represents the response of the payload position and Figure 8 shows the position error of the payload and rope tension variation. In the uncompensated case, the amplitude of the residual vibration of the payload position has continued until the end of the experiment. However, in the controlled cases, the vibrations are swiftly suppressed and the UUB+IOLC shows superior performance over the other controllers.

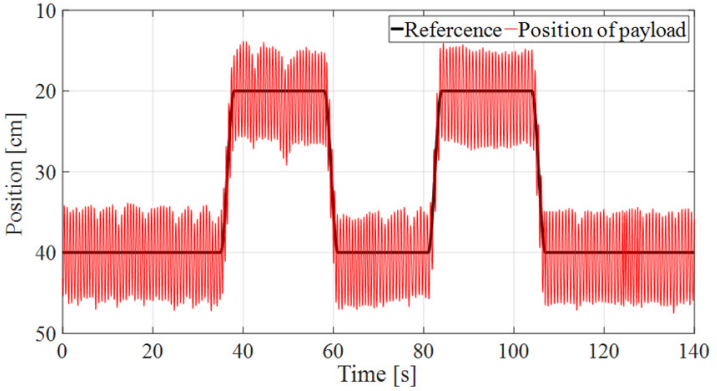

(a)

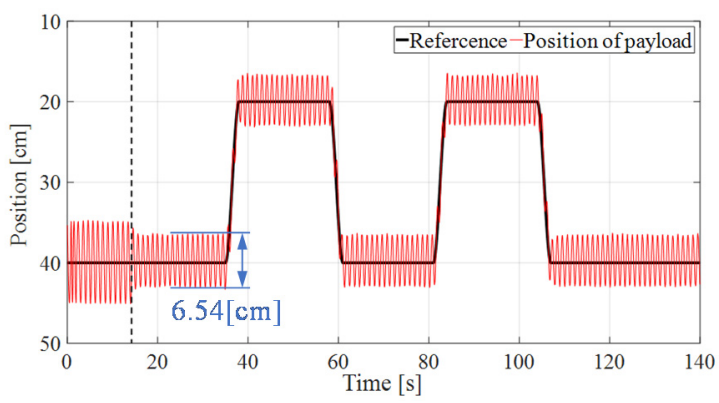

(c)

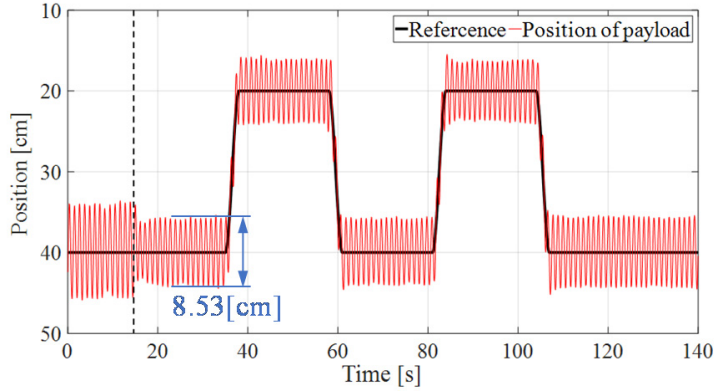

(b)

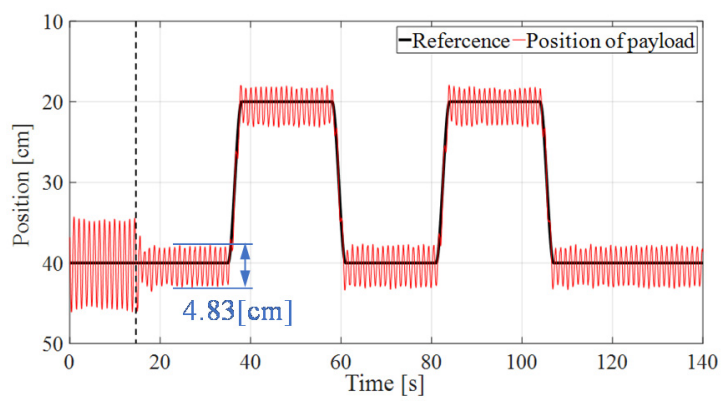

(d)

Figure 7. Payload position response from the experiment with the nominal system. The payload position tracking of the desired position without compensation (a), with the IOLC (b), with the ISMC (c), and with the UUB+IOLC (d). 


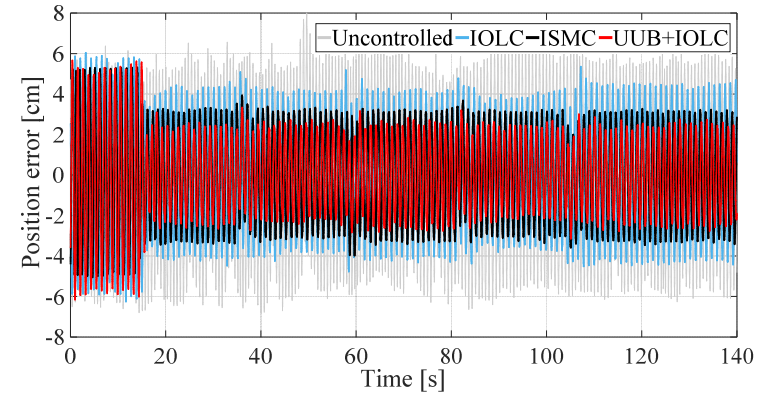

(a)

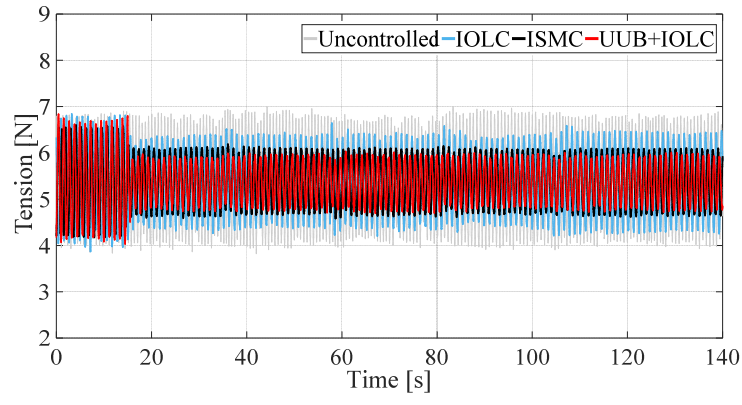

(b)

Figure 8. The experimental results with the nominal system. The payload position error (a), and the rope tension error (b).

\subsection{Experimental Result with the Uncertain System}

In practice, the actual system parameters cannot be measured precisely; thus, the robustness of the control system is required to cope with the parametric uncertainties. For this reason, in this section, the experiment with the uncertain system is conducted to test the robustness of the proposed control system.

To configure the parametric uncertainties, we introduce two types of 3D printed models inspired by subsea installation systems, as shown in Figure 9.

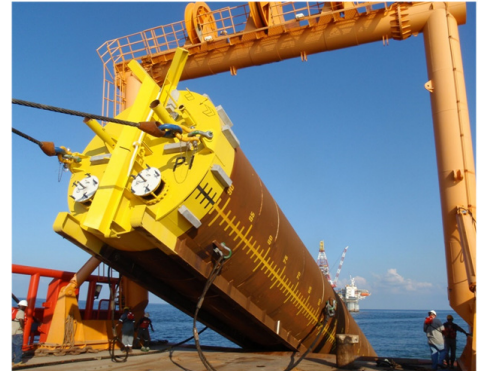

(a)

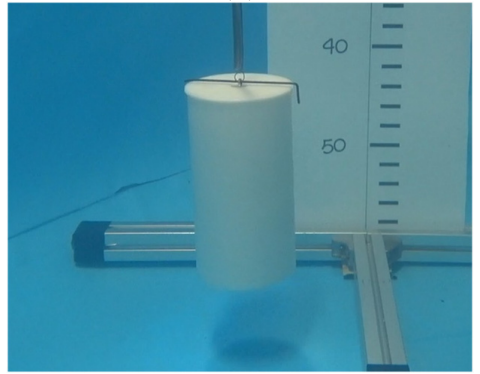

(c)

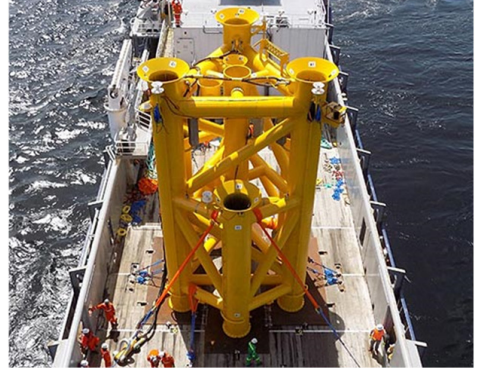

(b)

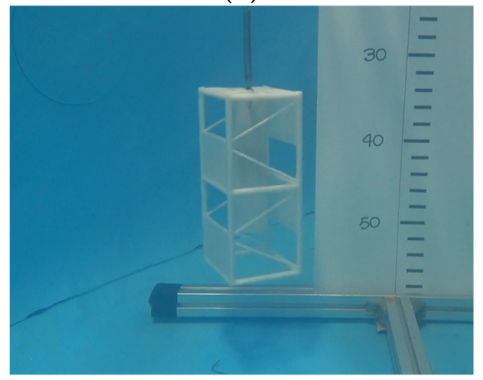

(d)

Figure 9. 3D printed models for configuration of parametric uncertainty. Examples of the actual subsea installations; a suction pile (a) and a truss structure (b). The 3D printed models of the suction pile (c) and the truss structure (d).

Additional mass is attached to the center of each 3D printed model. Using these models, the hydrodynamic coefficient of the payload obtained is different from its nominal value. Furthermore, we reduced the number of both weights and springs to two, respectively. That is, the total mass of the weights is $0.4 \mathrm{~kg}$ and the spring constant is $65.4 \mathrm{~N} / \mathrm{m}$.

Using the system configuration and controller gains defined in Section 4.1, we conduct the experimental tests following the same procedure described in Section 4.2. The performance index results of each control scheme are listed in Table 5. As shown in this table, the IAE value of the ISMC applied on the suction pile appears to be the smallest value when the output power of the wave generator is at $20 \%$. 
Table 5. Performance index values of each wave case and payload type.

\begin{tabular}{ccccc}
\hline & Output Power & $\mathbf{2 0} \%$ & $\mathbf{4 0 \%}$ & $\mathbf{6 0 \%}$ \\
\hline \multirow{4}{*}{ Suction Pile } & Uncompensated $^{1}()^{2}$ & $83.7806(1)$ & $438.7291(1)$ & $137.7685(1)$ \\
& IOLC & $40.5978(0.4)$ & $214.4034(0.49)$ & $84.1417(0.61)$ \\
& ISMC & $32.0787(0.38)$ & $169.8621(0.39)$ & $64.0237(0.46)$ \\
& UUB+IOLC & $38.0967(0.45)$ & $133.635(0.30)$ & $56.6176(0.41)$ \\
\hline \multirow{2}{*}{ Truss structure } & Uncompensation & $67.5714(1)$ & $382.9903(1)$ & $187.334(1)$ \\
& IOLC & $62.0795(0.92)$ & $216.4755(0.57)$ & $134.8257(0.72)$ \\
& ISMC & $44.2838(0.66)$ & $187.1458(0.49)$ & $112.669(0.60)$ \\
& UUB+IOLC & $44.4611(0.66)$ & $159.489(0.42)$ & $104.9172(0.56)$ \\
\hline
\end{tabular}

${ }^{1}$ Value of integral of absolute error $(J) .{ }^{2}$ Relative value of performance index to the uncompensated case (Jelative).

Furthermore, while experimenting with the truss structure, in the $20 \%$ case, the IAE values of the ISMC are similar to those of the UUB+IOLC. However, UUB+IOLC shows the smallest IAE values in the other cases.

From these results, when the wave disturbance is not strong, the ISMC performs better tracking of the desired payload position compared to other controllers. On the other hand, UUB+IOLC copes more effectively with strong disturbances in comparison with other control configurations.

The experiment results with the uncertain system are presented in Figures 10 and 11. Note that only the results when the power output is at $40 \%$ with the suction pile are introduced-since it is the worst case. Figure 10 illustrates the payload position response. Figure 11, on the other hand, depicts the position error of the payload as well as the resulting rope tension. Figure $10 \mathrm{~b}$ shows that the tension variation range when the controller is switched-off is larger than the nominal case. This implies that the impact of the hydrodynamic forces on the 3D printed payload is significantly greater than with the nominal payload. After the controller is switched on, both the ISMC and the UUB+IOLC control system suppress the amplitude of the payload position error as well as the rope tension variations. However, over time, the IOLC control system was not able to attenuate the amplitude of the payload position variations.

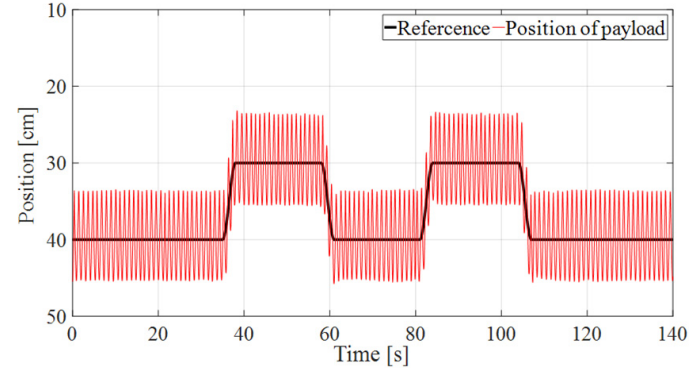

(a)

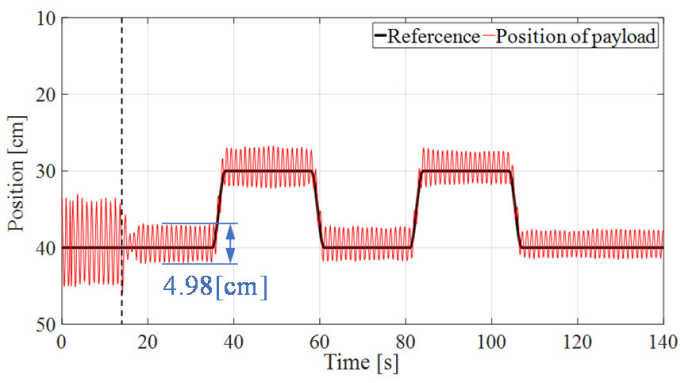

(c)

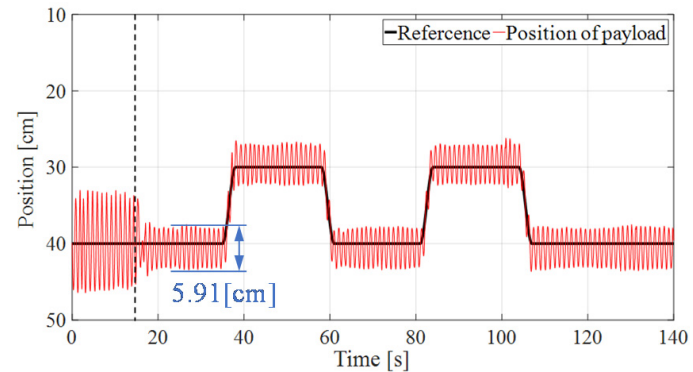

(b)

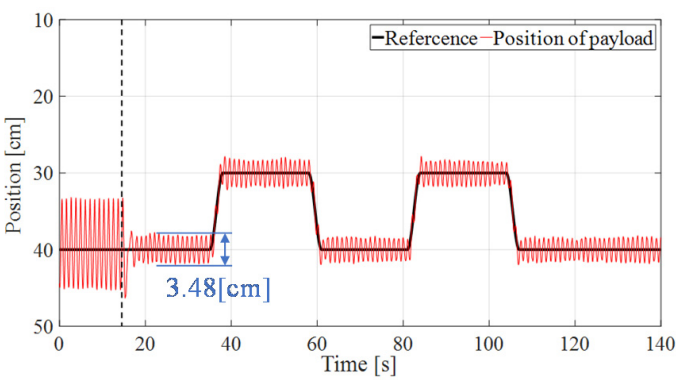

(d)

Figure 10. Payload position response from the experiment with the uncertain system. The payload position tracking without compensation (a), with the IOLC (b), with the ISMC (c), and with the UUB+IOLC (d). 


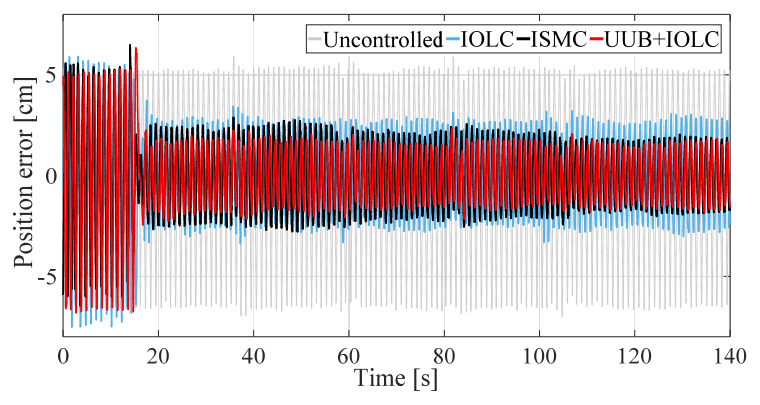

(a)

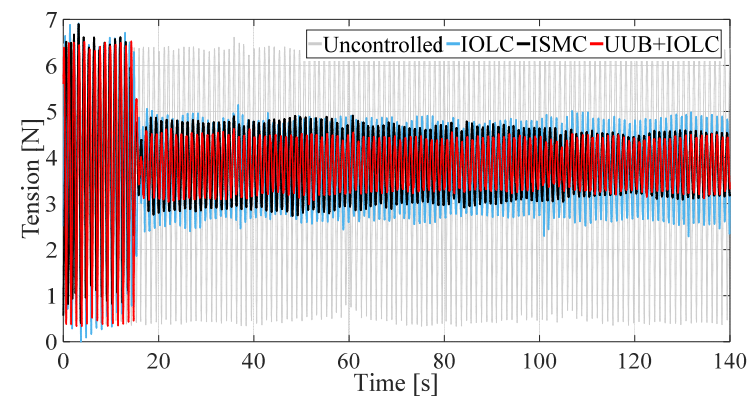

(b)

Figure 11. The experimental results with the uncertain system. The payload position error (a), and the rope tension error (b).

\section{Conclusions}

In this paper, the authors suggested a control scheme for payload position control of an offshore crane system. This study focused mainly on the dynamic modeling of the offshore crane and robust control system design for controlling the payload position.

The system dynamics were derived with kinematic and kinetic analysis, where the rotational motion, as well as the vertical motion of the offshore crane, was considered as the main representation of the system dynamics. The analysis procedure of the dynamic model was shown in a constructive form, such that deriving the dynamic model of a higher dimension system was possible.

The proposed controller consists of two components. The first control component is the IOLC that includes the disturbance decoupling term, and the second component is a UUB-based controller satisfying the UUB condition of the closed-loop system of an IOLC control system. On another note, the ISMC was introduced to carry out a comparison between the performance of the proposed controller and three additional control schemes.

The experiments were conducted to show the efficiency of the proposed controller. A two-scenario experimental study was conducted. The first scenario is when the parametric uncertainties were omitted, and the second is when these uncertain terms were taken into consideration. The performance of the proposed controller has been compared with that of an IOLC and an ISMC control system. The control performance-tracking of the desired position and suppressing the rope tension variations-of the ISMC control system with parametric uncertainties was good. The IAE value of the ISMC applied on the suction pile (when the power output is at $20 \%$ ) represents $79.0 \%$ of that of the IOLC and $84.2 \%$ of the UUB+IOLC's. Additionally, in the case of the truss structure, this value decreases to $71.3 \%$ of the IOLC's, but it remains almost the same as the one of the UUB+IOLC. However, with strong disturbances (when the wave generator output power is at $40 \%$ and $60 \%$ ) and parametric uncertainties, the proposed controller showed its superiority over other controllers thanks to the disturbance decoupling term and the energy-based compensation term. For instance, in the experiments conducted with the suction pile, the IAE value of the UUB+IOLC when the power output is at $40 \%$ is $62.3 \%$ of that of the IOLC and $78.7 \%$ of the ISMC's. In future work, a higher dimensional compensation structure and control system design will be introduced for the precise control of the payload position.

Author Contributions: Conceptualization, Y.-B.K.; methodology, H.-C.P., and D.-H.L.; software, D.H.L.; validation, D.-H.L., H.-C.P., and Y.-B.K.; writing—original draft preparation, D.-H.L.; writingreview and editing, Y.-B.K., H.-C.P., and S.C.; supervision, Y.-B.K. All authors have read and agreed to the published version of the manuscript.

Funding: This research received no external funding.

Conflicts of Interest: The authors declare no conflict of interest. 


\section{References}

1. Woodacre, J.K.; Bauer, R.J.; Irani, R.A. A review of vertical motion heave compensation systems. Ocean. Eng. 2015, 104, 140-154. [CrossRef]

2. Southerland, A. Mechanical Systems for Ocean Engineering. Nav. Eng. J. 1970, 82, 63-74. [CrossRef]

3. Messineo, S.; Celani, F.; Egeland, O. Crane feedback control in offshore moonpool operations. Control Eng. Pract. 2008, 16, 356-364. [CrossRef]

4. Messineo, S.; Serrani, A. Offshore crane control based on adaptive external models. Automatica 2009, 45, 2546-2556. [CrossRef]

5. Sagatun, S.I.; Johansen, T.A.; Fossen, T.I.; Nielsen, F.G. Wave synchronizing crane control during water entry in offshore moonpool operations. In Proceedings of the Proceedings of the International Conference on Control Applications, IEEE, Glasgow, UK, 18-20 September 2002; pp. 174-179.

6. Johansen, T.A.; Fossen, T.I.; Sagatun, S.I.; Nielsen, F.G. Wave synchronizing crane control during water entry in offshore moonpool operations-experimental results. IEEE J. Ocean. Eng. 2003, 28, 720-728. [CrossRef]

7. Do, K.D.; Pan, J. Nonlinear control of an active heave compensation system. Ocean. Eng. 2008, 35, 558-571. [CrossRef]

8. Neupert, J.; Mahl, T.; Haessig, B.; Sawodny, O.; Schneider, K. A heave compensation approach for offshore cranes. In Proceedings of the 2008 American Control Conference, IEEE, Seattle, WA, USA, 11-13 June 2008; pp. 538-543.

9. Küchler, S.; Mahl, T.; Neupert, J.; Schneider, K.; Sawodny, O. Active Control for an Offshore Crane Using Prediction of the Vessel's Motion. IEEE/ASME Trans. Mechatron. 2011, 16, 297-309. [CrossRef]

10. Isidori, A. Nonlinear Control Systems, 3rd ed.; Communications and Control Engineering; Springer: London, UK, 1995; ISBN 978-14471-3909-6.

11. Guillard, H.; Bourlès, H. Robust feedback linearization. In Proceedings of the Proceedings of the 14th International Symposium of Mathematical Theory of Networks and Systems, Perpignan, France, 19-23 June 2000.

12. Karimi, H.R.; Motlagh, M.R.J. Robust Feedback Linearization Control for a non Linearizable MIMO Nonlinear System in the Presence of Model Uncertainties. In Proceedings of the 2006 IEEE International Conference on Service Operations and Logistics, and Informatics, IEEE, Shanghai, China, 21-23 June 2006; pp. 965-970.

13. Franco, A.L.D.; Bourlès, H.; De Pieri, E.R. Robust Feedback Linearization without Full State Information. IFAC Proc. Vol. 2007, 40, 70-75. [CrossRef]

14. Norsahperi, N.M.H.; Danapalasingam, K.A. An improved optimal integral sliding mode control for uncertain robotic manipulators with reduced tracking error, chattering, and energy consumption. Mech. Syst. Signal. Process. 2020, $142,106747$. [CrossRef]

15. Tho, H.D.; Tasaki, R.; Terashima, K.; Tsume, M.; Suzuki, K. Robust Sliding Mode Control of a Rotary Hook. IFAC-PapersOnLine 2017, 50, 6060-6066. [CrossRef]

16. Tho, H.D.; Terashima, K. Robust Control Designs of Payload's Skew Rotation in a Boom Crane System. IEEE Trans. Control Syst. Technol. 2019, 27, 1608-1621. [CrossRef]

17. Lee, J.-H. Highly robust position control of BLDDSM using an improved integral variable structure systems. Automatica 2006, 42, 929-935. [CrossRef]

18. Cui, R.; Chen, L.; Yang, C.; Chen, M. Extended State Observer-Based Integral Sliding Mode Control for an Underwater Robot With Unknown Disturbances and Uncertain Nonlinearities. IEEE Trans. Ind. Electron. 2017, 64, 6785-6795. [CrossRef]

19. Fang, Y.; Wang, P.; Sun, N.; Zhang, Y. Dynamics analysis and nonlinear control of an offshore boom crane. IEEE Trans. Ind. Electron. 2014, 61, 414-427. [CrossRef]

20. Küchler, S.; Sawodny, O. Nonlinear control of an active heave compensation system with time-delay. In Proceedings of the 2010 IEEE International Conference on Control Applications, IEEE, San Antonio, TX, USA, 8-10 September 2010; pp. 1313-1318.

21. Skaare, B.; Egeland, O. Parallel Force/Position Crane Control in Marine Operations. IEEE J. Ocean. Eng. 2006, 31, 599-613. [CrossRef]

22. Lee, D.H.; Kim, T.W.; Park, H.C.; Kim, Y.B. A study on the modeling and dynamic analysis of the offshore crane and payload. J. Korean Soc. Fish. Technol. 2020, 56, 61-70. [CrossRef]

23. Richter, M.; Arnold, E.; Schneider, K.; Eberharter, J.K.; Sawodny, O. Model predictive trajectory planning with fallback-strategy for an active Heave Compensation system. In Proceedings of the 2014 American Control Conference, IEEE, Portland, OR, USA, 4-6 June 2014; pp. 1919-1924.

24. de Queiroz, M.S.; Dawson, D.M.; Nagarkatti, S.P.; Zhang, F. Lyapunov-Based Control of Mechanical Systems; Birkhäuser Boston: Boston, MA, USA, 2000; Volume 53, ISBN 978-1-4612-7108-6.

25. Aguilar-Avelar, C.; Moreno-Valenzuela, J. A composite controller for trajectory tracking applied to the Furuta pendulum. ISA Trans. 2015, 57, 286-294. [CrossRef] [PubMed]

26. Khalil, H.K. Nonlinear Systems, 3rd ed.; Prentice Hall: Upper Saddle River, NJ, USA, 2002; ISBN 0130673897.

27. Slotine, J.J.E.; Li, W. Applied Nonlinear Control; Prentice Hall: Englewood Cliffs, NJ, USA, 1991; ISBN 0130408905.

28. Tho, H.D.; Tasaki, R.; Kaneshige, A.; Miyoshi, T.; Terashima, K. Robust Sliding Mode Control with Integral Sliding surface of an underactuated rotary hook system. In Proceedings of the 2017 IEEE International Conference on Advanced Intelligent Mechatronics (AIM), IEEE, Munich, Germany, 3-7 July 2017; pp. 998-1003.

29. Lee, D.-H.; Kim, T.-W.; Ji, S.-W.; Kim, Y.-B. A study on load position control and vibration attenuation in crane operation using sub-actuator. Meas. Control 2019, 52, 794-803. [CrossRef] 